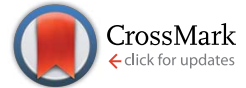

Cite this: Chem. Sci., 2016, 7, 3279

\title{
Small molecule regulated dynamic structural changes of human G-quadruplexes $\uparrow$
}

\author{
Manish Debnath, ${ }^{a}$ Shirsendu Ghosh, ${ }^{\mathrm{b}}$ Deepanjan Panda, ${ }^{a}$ Irene Bessi, ${ }^{\mathrm{c}}$ \\ Harald Schwalbe, ${ }^{c}$ Kankan Bhattacharyya ${ }^{\mathrm{b}}$ and Jyotirmayee Dash ${ }^{\star a}$
}

\begin{abstract}
The changes in structure and dynamics of oncogenic (c-MYC) and telomeric ( $h$-TELO) G-rich DNA sequences due to the binding of a novel carbazole derivative (BTC) are elucidated using single-molecule Förster resonance energy transfer (sm-FRET), fluorescence correlation spectroscopy (FCS) and NMR spectroscopy. In contrast to the previous reports on the binding of ligands to pre-folded G-quadruplexes, this work illustrates how ligand binding changes the conformational equilibria of both unstructured G-rich DNA sequences and $\mathrm{K}^{+}$-folded G-quadruplexes. The results demonstrate that $\mathrm{K}^{+}$free $c-M Y C$ and $h-T E L O$ exist as unfolded and partially folded conformations. The binding of BTC shifts the equilibria of both investigated DNA sequences towards the folded G-quadruplex structure, increases the diffusion coefficients and induces faster end-to-end contact formation. BTC recognizes a minor conformation of the C-MYC quadruplex and the two-tetrad basket conformations of the $h$-TELO quadruplex.
\end{abstract}

Received 6th January 2016

DOI: $10.1039 / c 6 s c 00057 f$

www.rsc.org/chemicalscience

Single-molecule Förster resonance energy transfer (sm-FRET)

\section{Introduction}

Ligand-mediated stabilization of G-quadruplexes is considered a promising strategy for the development of anti-cancer therapeutics as well as DNA-nanotechnology. ${ }^{1-6}$ However, little is known about how ligands can affect the conformational dynamics of G-quadruplexes. G-quadruplexes are associated with the transcriptional regulation of various oncogenes (c-MYC, ${ }^{7} c$-KIT1 ${ }^{8} c$-KIT2 (ref. 9) etc.) and telomere maintenance.$^{10}$ Consequently, small molecules that can bind G-quadruplexes are considered potential anticancer agents. ${ }^{1-5,10}$ Small molecule-induced stabilization of G-quadruplexes with or without cations has been studied by a variety of biophysical techniques. ${ }^{11-18}$ Most of the previous studies report the interaction of pre-folded static G-quadruplexes with small molecules. Human G-quadruplexes are, however, highly dynamic. ${ }^{19}$ Characterizing the conformational equilibria of unstructured G-rich DNA sequences in the presence and absence of small molecules might prove useful for innovative drug design.

${ }^{a}$ Department of Organic Chemistry, Indian Association for the Cultivation of Science, Jadavpur, Kolkata-700032, India. E-mail: ocjd@iacs.res.in

${ }^{b}$ Department of Physical Chemistry, Indian Association for the Cultivation of Science, Jadavpur, Kolkata-700032, India

'Institute of Organic Chemistry and Chemical Biology, Goethe University Frankfurt and Center for Biomolecular Magnetic Resonance (BMRZ), Max-von-Laue Strasse 7, 60438, Frankfurt am Main, Germany

$\dagger$ Electronic supplementary information (ESI) available: Experimental details, synthetic procedures, characterization data of compounds, ${ }^{1} \mathrm{H}$ NMR and ${ }^{13} \mathrm{C}$ NMR spectra, sm-FRET, shot noise, FCS-FRET data, lifetime data, CD spectra, NMR spectra. See DOI: 10.1039/c6sc00057f is a powerful method that provides key information about the structure, population distribution of folded or unfolded species and the end-to-end distance of bio-molecules. ${ }^{19-35}$ It has been used to investigate the effect of binding of either protein ${ }^{26}$ or metal ions $\left(\mathrm{K}^{+} / \mathrm{Na}^{+}\right)^{27-29}$ on the conformational dynamics of $\mathrm{G}^{-}$ quadruplexes. However, only a few studies have been conducted to elucidate the influence of small molecules on the conformational dynamics of G-quadruplex DNA. ${ }^{30,31}$

Fluorescence correlation spectroscopy (FCS) tracks single or several molecules in solution to investigate changes in diffusion coefficients, molecular size and intra-molecular contact dynamics. $^{32-38}$ FCS has been used to investigate the intramolecular dynamics of a DNA hairpin tagged with a donoracceptor FRET pair. ${ }^{36-38} \mathrm{~A}$ combination of sm-FRET and FCS has been used by Majima and co-workers to quantitatively analyse the $\mathrm{pH}$-induced intra-molecular folding dynamics of an i-motif DNA. ${ }^{39}$ We herein illustrate the changes in structure and dynamics in unstructured and $\mathrm{K}^{+}$-folded $c-M Y C$ and $h$-TELO DNA G-quadruplex forming sequences triggered by a G-quadruplex binding ligand bis-triazolylcarbazole ${ }^{40}$ (BTC) using a combination of sm-FRET and FCS. Interaction of BTC with G-quadruplexes has also been substantiated by FRET melting, circular dichroism, fluorescence lifetime and NMR spectroscopy studies.

\section{Results and discussion}

\section{BTC induced stabilization of G-quadruplex forming sequences in the absence of $\mathrm{K}^{+}$}

FRET melting analysis determines ligand-induced stabilization of folded G-quadruplex structures. ${ }^{41}$ We have examined the 
effect of BTC on the melting profile of both folded and unfolded $c-M Y C$ and $h$-TELO G-quadruplexes. We have used dual labeled $c$-MYC-(A) and $h$-TELO-(A) quadruplexes and a hairpin duplex $(d s)$ DNA control with FAM-TAMRA donor (D)-acceptor (A) FRET pairs (Fig. 1a).

Following our recently developed procedure, BTC was prepared using a one-pot $\mathrm{Cu}(\mathrm{I})$ catalyzed azide and alkyne cycloaddition in high yields ${ }^{\mathbf{4 0}}$ (Fig. 1b, and S1, ESI $\dagger$ ). FRET melting revealed that BTC exhibits maximum stabilization potentials for $\mathrm{K}^{+}$-folded $c-M Y C$-(A) and $h$-TELO-(A) (i.e. preannealed in $\mathrm{K}^{+}$buffer) with $\Delta T_{\mathrm{m}}$ values of $24.0^{\circ} \mathrm{C}$ and $38.7^{\circ} \mathrm{C}$, respectively. It is important to note that BTC shows a similar increase in the $T_{\mathrm{m}}$ values of unfolded $c-M Y C$-(A) and $h$-TELO-(A) sequences (Fig. 1c and Table S1, ESI $\dagger$ ). These results indicate that BTC can stabilize $c-M Y C$-(A) and $h$-TELO-(A) G-quadruplexes even in the absence of $\mathrm{K}^{+}$ions (Fig. 1d). ${ }^{40}$ Furthermore, BTC is found to be selective for G-quadruplexes over duplex DNA as it did not significantly alter the $T_{\mathrm{m}}$ value of duplex $(d s)$ DNA (Table $\mathrm{S} 1, \mathrm{ESI} \dagger)$.
BTC induced dynamic transitions between the ensembles of unfolded conformations to the folded state in G-quadruplexes

We then measured the sm-FRET between the donor-acceptor fluorophores to monitor the conformational changes in $\mathrm{K}^{+}$-free and $\mathrm{K}^{+}$-folded $c-M Y C$-(A) and $h$-TELO-(A) sequences induced by the binding of BTC.

Dual labeled sequences of the highest purity are used to exclude the signals from the donor only sample and no appreciable donor bleaching is observed under current experimental conditions (Fig. S2 and S3, ESI $\dagger$ ). We observed that the donoracceptor fluorescence intensities of the dual-labeled G-rich sequences produce anti-correlated fluctuations in the presence and absence of BTC and $\mathrm{K}^{+}$ions (Fig. 2 and S4, ESI $\dagger$ ). The histograms obtained from the time traces were fitted with triand single Gaussian distributions (Fig. 2b and S5, ESI $\dagger$ ). The contributions of shot noise in each FRET peak are determined (Table S2, ESI $\dagger$ ). The analysis of the FRET histogram of $\mathrm{K}^{+}$-free $c$ MYC-(A) shows two major peaks with FRET efficiencies $\left(\varepsilon_{\text {FRET }}\right)$ centered at $\sim 0.4(30 \%)$ and $0.6(68 \%)$ (Table S3, ESI $\dagger$ ). The (a)

$$
c-M Y C
$$

(A) 5'-FAM-d(TGAG $\left.\mathrm{TG}_{3} \mathrm{TAG}_{3} \mathrm{TG}_{3} \mathrm{TA}_{2}\right)-T A M R A-3^{\prime}$

(B) $5^{\prime}-F A M-\mathrm{d}\left(\mathrm{TGAG}_{3} \mathrm{TG}_{3} \mathrm{TAG}_{3} \mathrm{TG}_{3} \mathrm{TA}_{2}\right)-3^{\prime}$

(C) 5'-d(TGAG $\left.\mathrm{TG}_{3} \mathrm{TAG}_{3} \mathrm{TG}_{3} \mathrm{TA}_{2}\right)-$ TAMRA-3'

(D) $5^{\prime}-\mathrm{d}\left(\mathrm{TGAG}_{3} \mathrm{TG}_{3} \mathrm{TAG}_{3} \mathrm{TG}_{3} \mathrm{TA}_{2}\right)-3^{\prime}$

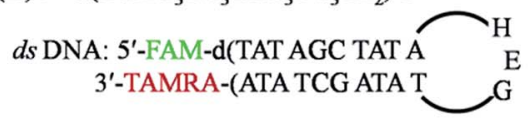

$h$-TELO

(A) 5'-FAM-d(G G $_{3}$ TAAG $_{3}$ TTAG $_{3}$ TTAG $\left._{3}\right)-$ TAMRA-3'

(B) $5^{\prime}-$ FAM $-\mathrm{d}\left(\mathrm{G}_{3} \mathrm{TTAG}_{3} \mathrm{TTAG}_{3} \mathrm{TTAG}_{3}\right)-3^{\prime}$

(C) 5'-d(G G $_{3}$ TAG $_{3}$ TTAG $_{3}$ TTAG $\left._{3}\right)-T A M R A-3^{\prime}$

(D) $5^{\prime}-\mathrm{d}\left(\mathrm{G}_{3} \mathrm{TTAG}_{3} \mathrm{TTAG}_{3} \mathrm{TTAG}_{3}\right)-3^{\prime}$

FAM $=$ Donor $;$ TAMRA $=$ Acceptor

(b) HEG = Hexaethylene glycol linker

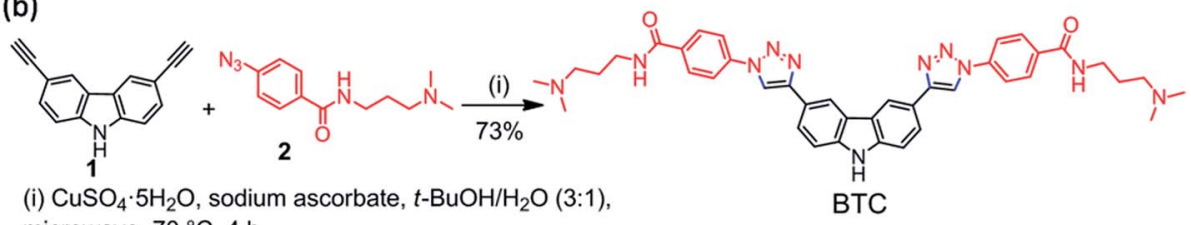
microwave, $70^{\circ} \mathrm{C}, 4 \mathrm{~h}$

(c)

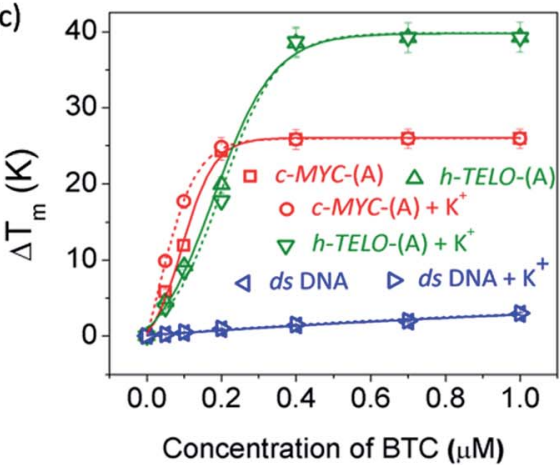

(d)

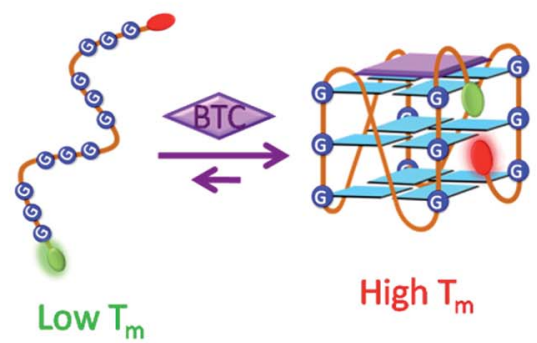

Fig. 1 (a) DNA sequences (c-MYC, $h$-TELO and ds DNA) used in this study, (b) one-pot synthesis of carbazole derivative BTC, (c) FRET melting profiles of $c-M Y C-(\mathrm{A}), h-T E L O-(\mathrm{A})$ and $d s$ DNA with increasing $[\mathrm{BTC}]$ in the presence and absence of $\mathrm{K}^{+} ; T_{\mathrm{m}}\left({ }^{\circ} \mathrm{C}\right)$ for $c-M Y C-(\mathrm{A})=(69 \pm 1), h-$ $T E L O-(A)=(55 \pm 1)$, and $d s$ DNA $=(57 \pm 1)$. (d) Schematic representations of a G-quadruplex formation by BTC induced folding of a G-rich strand. 

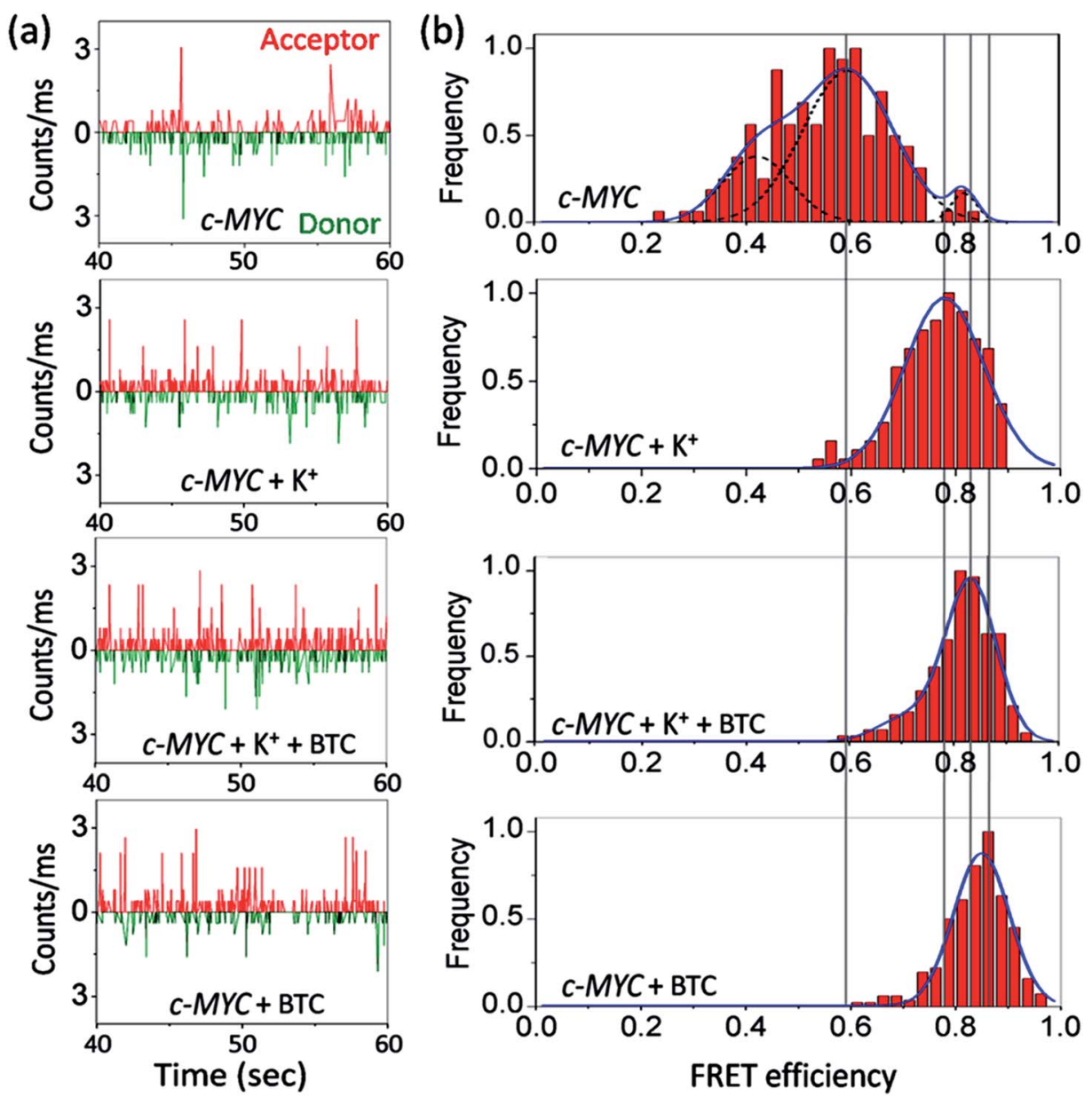

Fig. 2 Photon bursts of donor/acceptor (background corrected) (a), and FRET efficiency distributions (b) of 100 pM dual fluorescently labeled cMYC-(A) G-quadruplex forming sequence in the presence and absence of $\mathrm{K}^{+}$and BTC. For detailed information see Fig. S4 and S5, ESI. $\dagger$

distances between donor and acceptor $\left(R_{\mathrm{DA}}\right)$ dyes corresponding to each FRET state (0.4 and 0.6) calculated using eqn S3 (ESI $\dagger$ ), are $58.4 \AA$ and $51.7 \AA$, respectively. The FRET histogram of the $\mathrm{K}^{+}$-folded $c$-MYC-(A) shows only one major peak at $\sim 0.8(97 \%)$. Upon addition of BTC ( 1 equiv.), the single peak at $\sim 0.8$ is preserved in the histogram (Fig. 2b). The average $R_{\mathrm{DA}}$ determined for the $\mathrm{K}^{+}$-folded $c$-MYC-(A) in the presence and absence of BTC lies between $\sim 44-42 \AA$. Interestingly, the FRET distribution of the $\mathrm{K}^{+}$-free $c$-MYC-(A) in the presence of BTC exhibits a narrow peak (Fig. 2b) with higher efficiency $\left(\varepsilon_{\text {FRET }} \sim 0.85\right)$ corresponding to a $R_{\mathrm{DA}}$ value of $\sim 41 \AA$.

The FRET histogram of $\mathrm{K}^{+}$-free $h$-TELO-(A) shows a wide distribution (mean $\varepsilon_{\mathrm{FRET}} \sim 0.51$ ) with a $R_{\mathrm{DA}}$ of $\sim 54.6 \AA$ (Fig. S4, ESI $\dagger$ ). The $\mathrm{K}^{+}$-folded $h$-TELO-(A) shows a $\varepsilon_{\text {FRET }}$ value of $\sim 0.8$ with a $R_{\mathrm{DA}}$ of $\sim 45 \AA$. Upon addition of BTC to either $\mathrm{K}^{+}$-free or the $\mathrm{K}^{+}$folded $h$-TELO-(A), the $\varepsilon_{\text {FRET }}$ distribution is shifted towards a higher value $(\sim 0.9)$. The corresponding $R_{\mathrm{DA}}$ values were determined to be $\sim 40.6 \AA$ (BTC and $\mathrm{K}^{+}$) and $\sim 39 \AA$ (only BTC). Considering the presence of extra nucleotides and the dye linkers present in the dual labeled sequences, the $R_{\mathrm{DA}}$ values obtained for $c-M Y C$-(A) and $h$-TELO-(A) in the presence of $\mathrm{K}^{+}$and
BTC $(\sim 39-42 \AA)$, are close to the size of a folded G-quadruplex [diameter $\sim 25 \AA$ ] conformation.

In unfolded structures, the distances between the donor and acceptor fluorophores $\left(R_{\mathrm{DA}} \sim 54-58 \AA\right)$ are large and, consequently, the $\varepsilon_{\text {FRET }}$ values are small. The low FRET peak observed for the $\mathrm{K}^{+}$-free $c$-MYC-(A) sequence at $\varepsilon_{\text {FRET }} \sim 0.4$ may be assigned to the unfolded (single stranded) structure. The FRET state $\sim 0.6$ indicates the existence of an intermediate state, presumably an ensemble of partially folded structures. The high FRET peak ( 0.8-0.9) indicates the formation of G-quadruplex structures.

BTC-induced quadruplex formation is further corroborated by carrying out sm-FRET experiments using a dual labeled mutant $c-M Y C$ sequence (Fig. S6 and S7, ESI $\dagger$ ). Upon addition of BTC, the FRET histogram of $c-M Y C$-mut doesn't show any significant change in FRET efficiency. These results suggest that G-rich sequences primarily remain as unfolded and partially folded structures in the absence of BTC and $\mathrm{K}^{+}$. BTC apparently induces and shifts the equilibrium to a folded G-quadruplex conformation as evidenced by the shift of FRET histograms towards higher values. 
FCS measured ligand induced conformational fluctuations in G-quadruplex structures

In addition to sm-FRET, a combination of FCS with FRET is used to investigate the ligand-induced diffusion properties of $c$ $M Y C$-(A) and $h$-TELO-(A) sequences. The fluorescence fluctuations due to the diffusion and inter-conversion of the dual labeled G-rich sequences between the folded (high FRET) and unfolded (low FRET) states are analysed as they pass through the focal volume of the microscope. The resulting FCS curves are shown in Fig. 3a and c (Fig. S8, ESI $\dagger$ ). In FCS, the observed fluctuations in fluorescence intensity are expressed as timecorrelation functions, $G(\tau)^{39}$ (eqn (1)).

$$
G(\tau)=\frac{1}{N}\left[1+\frac{\tau}{\tau_{\text {diff }}}\right]^{-1}\left[1+K_{\mathrm{obs}}^{\mathrm{C}} \times \exp \left(-\frac{\tau}{\tau_{\mathrm{obs}}^{\mathrm{C}}}\right)\right]
$$

Where $N$ is the average number of labeled DNA sequences in the observed volume, $\tau_{\mathrm{D}}$ is the molecular diffusion time, $K_{\mathrm{obs}}^{\mathrm{C}}$ is the observed amplitude of the donor-acceptor contact formation kinetics due to changes of the donor-acceptor distance, and $\tau_{\mathrm{obs}}^{\mathrm{C}}$ is the observed time of donor-acceptor contact formation.

The diffusion coefficients $\left(D_{\mathrm{t}}\right)$ were calculated from the diffusion time $\left(\tau_{\mathrm{D}}\right)$ using equation S8, ESI $\dagger$ (Tables 1 and S4, ESI $\dagger$ ). The $D_{\mathrm{t}}$ of $\mathrm{K}^{+}$-free $c-M Y C$-(A) is $221 \mu \mathrm{m}^{2} \mathrm{~s}^{-1}$ and increases to $296 \mu \mathrm{m}^{2} \mathrm{~s}^{-1}$ in the $\mathrm{K}^{+}$-folded conformation. Similarly, the $D_{\mathrm{t}}$ (a)

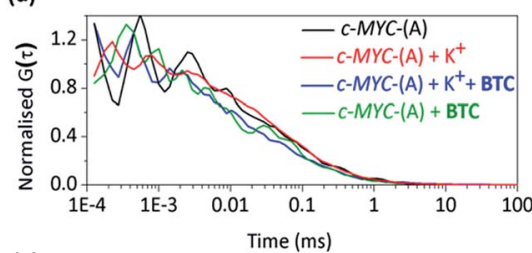

(c)

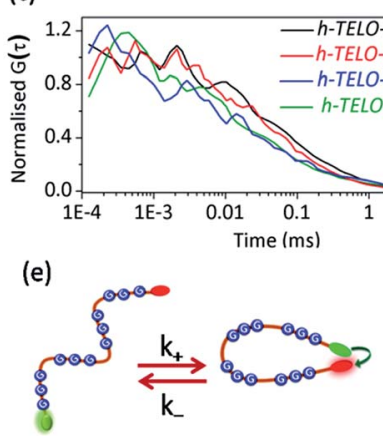

(f) (b)

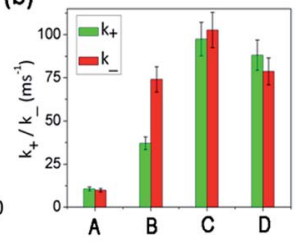

(d)

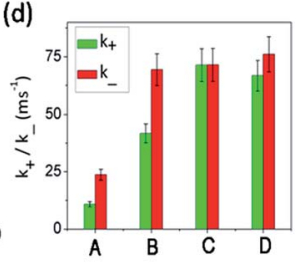

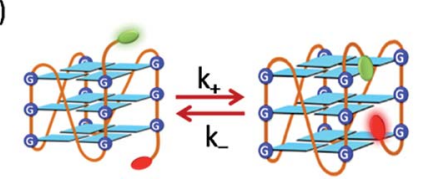

Fig. 3 The autocorrelation traces of FAM-TAMRA dual labeled (a) CMYC-(A) in the presence and absence of $\mathrm{K}^{+}$and BTC. (b) Plots representing change in rate constant for donor-acceptor contact formation $\left(k_{+}\right)$and dissociation $\left(k_{-}\right)$values of $\mathrm{K}^{+}$-free $c-M Y C-(\mathrm{A})$ [lane A]; $\mathrm{K}^{+}$-folded C-MYC-(A) [lane B]; BTC + $\mathrm{K}^{+}$-folded C-MYC-(A) [lane C]; $\mathrm{BTC}+\mathrm{K}^{+}$-free $\mathrm{C}-\mathrm{MYC}$-(A) [lane D]. (c) The autocorrelation traces of FAM-TAMRA dual labeled $h$-TELO-(A) in the presence and absence of $\mathrm{K}^{+}$and BTC. (d) Plots representing change in $k_{+}$and $k_{-}$values in $\mathrm{K}^{+}-$ free $h$-TELO-(A) [lane A]; $\mathrm{K}^{+}$-folded $h$-TELO-(A) [lane B]; BTC $+\mathrm{K}^{+}$folded $h$-TELO-(A) [lane C]; BTC $+\mathrm{K}^{+}$-free $h$-TELO-(A) [lane D]. Schemes showing the end-to-end contact formation in (e) unfolded DNA and (f) folded DNA. of the $\mathrm{K}^{+}$-free $h$-TELO-(A) increases in the $\mathrm{K}^{+}$-folded conformations (Tables 1 and S4, ESI $\dagger$ ). Addition of BTC to the $\mathrm{K}^{+}$-folded $c$ $M Y C$-(A) and $h$-TELO-(A) results in further increase in the $D_{\mathrm{t}}$ values to $314 \mu^{2} \mathrm{~s}^{-1}$ and $318 \mu^{2} \mathrm{~s}^{-1}$, respectively. It is intriguing to observe that the binding of BTC to the $\mathrm{K}^{+}$-free $c$ MYC-(A) and $h$-TELO-(A) increases the $D_{\mathrm{t}}$ values to $318 \mu \mathrm{m}^{2} \mathrm{~s}^{-1}$ and that is $\sim 43 \%$ and $\sim 32 \%$ higher compared to the $\mathrm{K}^{+}$-free $c$ MYC-(A) and h-TELO-(A) sequences. According to the StokesEinstein eqn (S10, ESI $\dagger$ ), the diffusion coefficient is inversely related to the hydrodynamic radii $\left(R_{\mathrm{h}}\right)$ for a freely diffusing molecule. Therefore, the observed increase in $D_{\mathrm{t}}$ of the $\mathrm{K}^{+}$-free $c$ MYC-(A) and $h$-TELO-(A) sequences can be attributed to a $\sim 43 \%$ and $\sim 32 \%$ decrease in $R_{\mathrm{h}}$ upon the binding of BTC. The decrease in $R_{\mathrm{h}}$ estimated theoretically from the ratio of frictional coefficients $\left(f / f_{0}\right)$ indicates that the binding of BTC to the $\mathrm{K}^{+}$-free $c$-MYC-(A) and $h$-TELO-(A) leads to a $\sim 50 \%$ reduction in the $R_{\mathrm{h}}$ values. In addition, the diffusion parameters calculated using eqn S19, ESI $\dagger$ are quite similar to those obtained from the simplified eqn (1) (Table S5, ESI $\dagger$ ). To further validate our findings, we carried out parallel diffusion experiments with single (FAM) labeled $c$-MYC-(B) and $h$-TELO-(B) G-quadruplex forming sequences (Fig. S9, ESI $\dagger$ ). The $\tau_{\mathrm{D}}$ values for single labeled $c-M Y C$-(B) and $h$-TELO-(B) in the presence and absence of BTC and $\mathrm{K}^{+}$ions are similar to those of the dual labeled $c$ $M Y C$-(A) and $h$-TELO-(A) sequences. Hence the covalent attachment of the dyes does not significantly impact the diffusion parameters (Fig. S9 and Table S6, ESI $\dagger$ ).

Next, the kinetic parameters for the end-to-end contact formation $\left(k_{+}\right)$and dissociation $\left(k_{-}\right)$of the $\mathrm{K}^{+}$-free and $\mathrm{K}^{+}$-folded quadruplexes are calculated (Fig. 3b and d, Tables 1 and S4, $\left.\mathrm{ESI}^{\dagger}\right)$. The end-to-end contact formation of $\mathrm{K}^{+}$-free DNA corresponds to the initial intra-chain contact formation during the Gquadruplex formation (Fig. 3e). ${ }^{42}$ In contrast, the $k_{+} / k_{-}$values of the folded quadruplexes indicate the motion of flanking sequences and the dye linkers (Fig. 3f). ${ }^{39}$ The $\mathrm{K}^{+}$-free $c$-MYC-(A) and $h$-TELO-(A) exhibit nearly identical $k_{+}$values of $\sim 10 \mathrm{~ms}^{-1}$. The $k_{+}$values are increased $\sim 3-4$ fold for the $\mathrm{K}^{+}$-folded $c-M Y C$ (A) and $h$-TELO-(A) quadruplexes. However, the $\mathrm{K}^{+}$-free $c-M Y C$ (A) and $h$-TELO-(A) sequences show $k_{-}$values of $9.8 \mathrm{~ms}^{-1}$ and $23.7 \mathrm{~ms}^{-1}$, respectively. The $\mathrm{K}^{+}$-folded $c$-MYC-(A) and $h$-TELO-(A)

Table 1 Table representing diffusion coefficients $\left(D_{t}\right)$, observed time of intra-chain contact formation $\left(\tau_{\text {obs }}^{\mathrm{C}}\right)$, and rate constants of donoracceptor contact formation $\left(k_{+}\right)$and dissociation $\left(k_{-}\right)$

\begin{tabular}{llrlc}
\hline System & $\begin{array}{l}D_{\mathrm{t}} \\
\left(\mu \mathrm{m}^{2} \mathrm{~s}^{-1}\right)\end{array}$ & $\begin{array}{l}\tau_{\mathrm{obs}}^{\mathrm{C}} \\
(\mu \mathrm{s})\end{array}$ & $\begin{array}{l}k_{+} \\
\left(\mathrm{ms}^{-1}\right)\end{array}$ & $\begin{array}{l}k_{-} \\
\left(\mathrm{ms}^{-1}\right)\end{array}$ \\
\hline$c-M Y C-(\mathrm{A})$ & 221 & 49 & $10.6 \pm 1.1$ & $9.8 \pm 1$ \\
$c-M Y C-(\mathrm{A})+\mathrm{K}^{+}$ & 296 & 9 & $37.0 \pm 4$ & $74.0 \pm 7$ \\
$c-M Y C-(\mathrm{A})+\mathrm{K}^{+}+$BTC & 318 & 5 & $97.4 \pm 10$ & $102.6 \pm 11$ \\
$c-M Y C-(\mathrm{A})+$ BTC & 318 & 6 & $88.0 \pm 9$ & $78.6 \pm 8$ \\
$h-T E L O-(\mathrm{A})$ & 242 & 29 & $10.8 \pm 1.1$ & $23.7 \pm 2.5$ \\
$h-T E L O-(\mathrm{A})+\mathrm{K}^{+}$ & 283 & 9 & $41.7 \pm 4.3$ & $69.4 \pm 7$ \\
$h-T E L O-(\mathrm{A})+\mathrm{K}^{+}+$BTC & 314 & 7 & $71.4 \pm 7.4$ & $71.5 \pm 7$ \\
$h-T E L O-(\mathrm{A})+$ BTC & 318 & 7 & $66.8 \pm 7$ & $76.1 \pm 8$ \\
& $D_{\mathrm{t}}, \tau_{\mathrm{obs}}^{\mathrm{C}}= \pm 10 \%$ & &
\end{tabular}


quadruplexes exhibit a 7 -fold and a 3 -fold increase in $k_{-}$values, respectively. Upon binding to the BTC, $c-M Y C$-(A) displays an $\sim 8-10$ fold increase and the $h$-TELO-(A) displays a $\sim 6.0$ and a $\sim 3.0$ fold increase in the $k_{+}$and $k_{-}$values, respectively. Interestingly, the $k_{+} / k_{-}$values obtained for single labeled $c-M Y C$ (B) and $h$-TELO-(B) are also comparable to those of $c-M Y C$-(A) and $h$-TELO-(A) (Fig. S9, Table S6, ESI $\dagger$ ).

We presumed that ligand-induced changes in diffusion parameters are associated with the conformation of the DNA. The $\mathrm{K}^{+}$-free DNA sequences have a large surface area, which causes increased hydration on the surface of the DNA. This creates a constraint in flexibility in $\mathrm{K}^{+}$-free DNA and consequently, the rates of intra-chain contact formation and dissociation $\left(k_{+} / k_{-}\right)$have lower values (Fig. 3e). However, the BTCmediated folding of $\mathrm{K}^{+}$-free DNA sequences into compact globular quadruplexes causes dehydration due to lower availability of the hydration sites resulting in high $k_{+}$and $k_{-}$values.

\section{Fluorescence lifetime monitored dynamics of DNA conformation distribution}

The influence of BTC on the conformational dynamics of $c-M Y C$ and $h$-TELO quadruplexes are further investigated by measuring the donor decay of single and dual labeled sequences (Fig. S10 and S11, ESI $\dagger)$. The rate constant of FRET $\left(k_{\text {FRET }}\right)$ between donor and acceptor can be expressed as a simple function of D-A distances $\left(R_{\mathrm{DA}}\right)$ :

$$
k_{\mathrm{FRET}}=\frac{1}{\tau_{\mathrm{D}}}\left(\frac{R_{0}}{R_{\mathrm{DA}}}\right)^{6}
$$

where, $R_{0}$ represents the Förster distance and the $k_{\text {FRET }}$ can be determined from the average lifetime $\left(\tau_{\mathrm{avg}}\right)$ of donor labeled $c$ $M Y C$-(B) and $h$-TELO-(B) $\left(\tau_{\mathrm{D}}\right)$ and donor-acceptor labeled $c-M Y C$ (A) and $h$-TELO-(A) ( $\left.\tau_{\mathrm{DA}}\right)$ (Tables S7 and S8, ESI $\dagger$ ) using eqn (3).

$$
\frac{1}{\tau_{\mathrm{DA}}}=\frac{1}{\tau_{\mathrm{D}}}+k_{\mathrm{FRET}}
$$

The $c-M Y C$-(A) exhibits a $k_{\text {FRET }}$ value of $\sim 0.8 \mathrm{~ns}^{-1}$ that increases to $\sim 1.3 \mathrm{~ns}^{-1}$ and $\sim 2.0 \mathrm{~ns}^{-1}$ in the presence of $\mathrm{K}^{+}$and BTC, respectively. A similar increase in the $k_{\text {FRET }}$ value is observed for $h$-TELO-(A) after the addition of $\mathrm{K}^{+}$and BTC, respectively. For further illustration, the $R_{\mathrm{DA}}$ of $c-M Y C$-(A) and $h$ TELO-(A) are estimated from the average FRET efficiency $\left(\varepsilon_{\text {avg }}\right)$ using eqn S21, ESI $\dagger$ (Tables S7 and S8, ESI $\dagger$ ). The calculated $R_{\mathrm{DA}}$ is $\sim 49 \AA$ for the $c-M Y C$-(A), $\sim 44 \AA$ for $\mathrm{K}^{+}$-folded $c-M Y C$-(A), $\sim 42 \AA$ for the BTC bound $\mathrm{K}^{+}$-folded $c-M Y C$-(A) and $\sim 39 \AA$ for the BTC folded $c-M Y C$-(A) conformations. For $h$-TELO-(A), the $R_{\mathrm{DA}}$ value decreases from $\sim 55 \AA$ in the $\mathrm{K}^{+}$-free-state to $\sim 44 \AA$ in $\mathrm{K}^{+}$-folded state and it reduces further to $41 \AA$ in the BTC-bound conformation. These distances are in close agreement with the smFRET data and demonstrate that the binding of BTC decreases the distance between the donor and acceptor labels, as compared to the $\mathrm{K}^{+}$-free and $\mathrm{K}^{+}$-folded $c$-MYC-(A) and $h$-TELO-(A) conformations. Together, these results indicate that BTC can template the formation of compact quadruplexes from the $\mathrm{K}^{+}$- free G-rich sequences that facilitate faster donor decay via donor-to-acceptor energy transfer.

\section{Analysis of ligand binding using NMR spectroscopy}

NMR analysis showed that in the presence of $\mathrm{K}^{+}, c-M Y C$-(D) exists as an equilibrium between a major parallel conformation, ${ }^{\mathbf{4 3}}$ and one or more minor conformations (Fig. 4a), possibly featuring an all-parallel strand scaffold but different capping structures. ${ }^{\mathbf{4 3 , 4 4}}$ Imino signals of the major conformation are labeled on the spectrum according to the numbering shown in
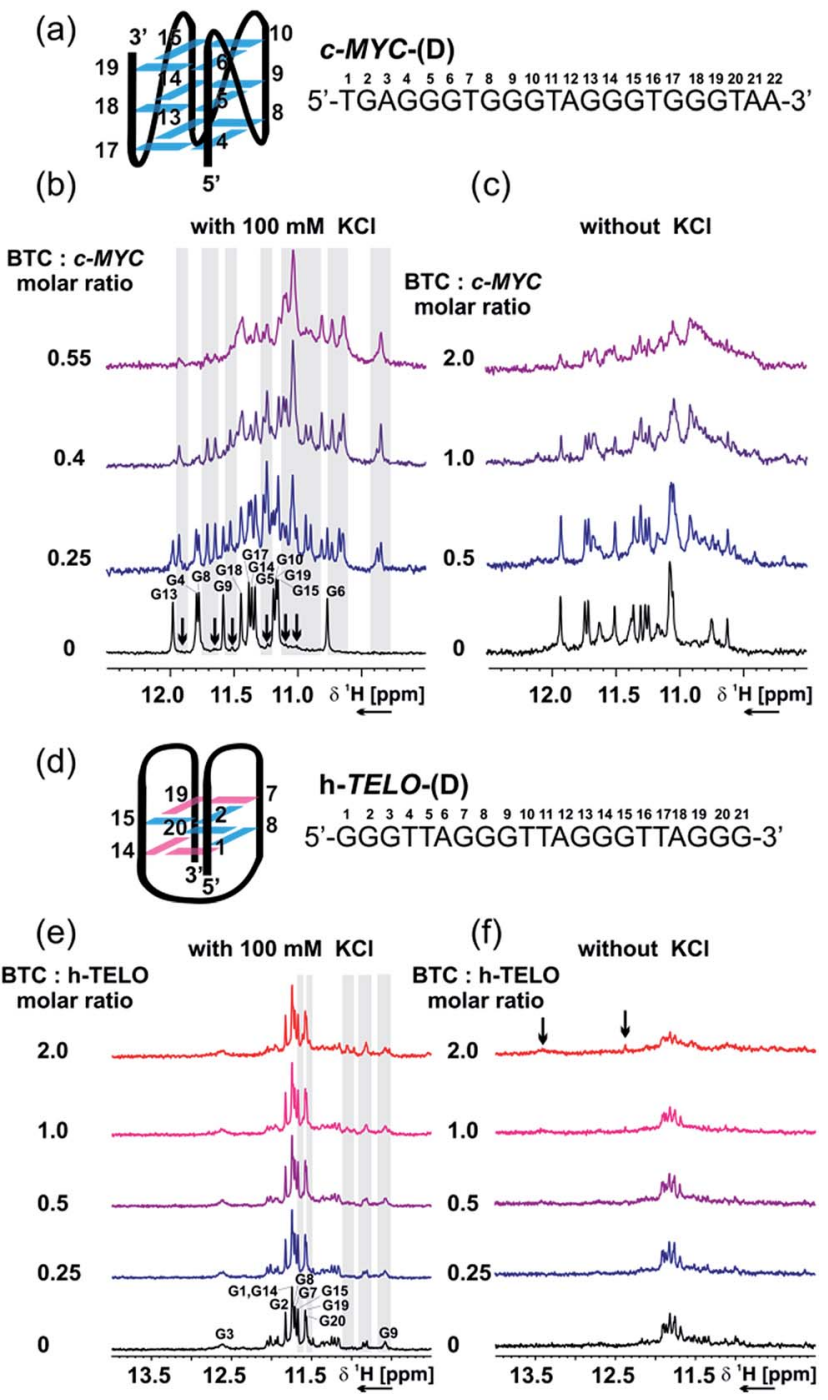

Fig. 4 NMR titration of $c-M Y C$-(D) and $h$-TELO-(D) in the presence and absence of BTC and $\mathrm{K}^{+}$. (a) Scheme of the major conformation of c-MYC-(D), as determined using NMR from Ambrus et al. ${ }^{43}$ [PDB code: $1 X A V]$, with sequence and numbering. Imino region of the $1 D^{1} \mathrm{H} N M R$ spectrum of $C-M Y C-(D)$ in the presence of an increasing amount of BTC, with (b) or without (c) $100 \mathrm{mM} \mathrm{KCl}$. (d) Scheme of the proposed structure of $h$-TELO-(D), with sequence and numbering. Imino region of the 1D ${ }^{1} \mathrm{H}$ NMR spectrum of $h-T E L O-(D)$ in the presence of an increasing amount of BTC, with (e) or without (f) $100 \mathrm{mM} \mathrm{KCl}$. Experimental conditions: $100 \mu \mathrm{M}$ DNA, $25 \mathrm{mM}$ Tris- $\mathrm{HCl}$ buffer $(\mathrm{pH}$ 7.4), $298 \mathrm{~K}, 600 \mathrm{MHz}$. Guanine residues in anti and syn conformations are represented in cyan and magenta, respectively. 
Fig. 4a, while signals of the minor conformations are indicated with black arrows. In the absence of $\mathrm{K}^{+}$, the $c-M Y C$-(D) sequence is partially pre-folded as a mixture of two or more conformations, as suggested by the signals detected in the imino region (Fig. 4c).

Addition of BTC to $c$-MYC-(D) shows that the ligand selectively interacts and stabilizes a minor conformation, both in the presence and absence of $\mathrm{K}^{+}$(Fig. 4c and d). The signals of the imino protons of the major conformation of $c-M Y C$-(D) are not perturbed by BTC. However, a set of signals, already detectable in the absence of BTC (minor conformation), becomes more intense upon the addition of ligand, which suggests that the ligand can interact with the $c-M Y C$-(D) quadruplex via conformational selection. As suggested by the CD data (Fig. S14, ESI $\dagger$ ), we propose that the minor conformation stabilized by BTC preserves the all-parallel scaffold of the major conformation (Fig. 4a), but presents different arrangements of the capping structures.

In $\mathrm{K}^{+}$containing buffer, the ${ }^{1} \mathrm{H}$ 1D imino pattern revealed that $h$-TELO-(D) exists predominantly as a 2 -tetrad basket quadruplex, probably with looser capping structures compared to the structure reported by Lim et al. ${ }^{17}$ (Fig. $4 \mathrm{~d}$ and e). Other minor conformations are also observed in the ${ }^{1} \mathrm{H}$ NMR spectra of the $h$-TELO-(D) quadruplex. Addition of BTC to the $h$-TELO pre-folded in the presence of $\mathrm{K}^{+}$induces weak chemical shift perturbations (highlighted with grey shadows, Fig. 4e) of the imino signals from the minor conformation and, possibly, from the guanine residues involved in the capping structure (G9 and G21). In the absence of $\mathrm{K}^{+}$, the $h$-TELO-(D) is found to be partially folded, as suggested by the imino signals detectable in the Hoogsteen hydrogen bond region (Fig. 4f).

Interestingly, upon addition of BTC, at a ratio [Ligand $]:[\mathrm{DNA}]=2$, a broad signal at $13.5 \mathrm{ppm}$, indicating the formation of a Watson/Crick (WC) base pair, and a sharp signal at $12.5 \mathrm{ppm}$, possibly arising from the carbazole $\mathrm{NH}$ group or from the newly formed Hoogsteen imino bonds between guanines, were detected. These findings suggest that in the absence of $\mathrm{K}^{+}$, BTC is able to promote the restructuring of the capping structures via formation of intra- or inter-loop WC-A : T interactions.

In contrast with that observed by sm-FRET (Fig. S4, ESI $\dagger$ ), the aromatic region of the ${ }^{1} \mathrm{H}$ NMR spectra of $h$-TELO-(D) (Fig. S14c and $\mathrm{d}, \mathrm{ESI} \dagger$ ) reveals that in the absence of $\mathrm{K}^{+}$, BTC is able to promote G-quadruplex folding only partially. Taken together, the NMR and CD data support the single-molecule results, confirming that the ligand is able to stabilize the $c-M Y C-(\mathrm{D})$ and $h$-TELO-(D) G-quadruplexes. However, the details of the interaction process, particularly in the absence of $\mathrm{K}^{+}$, might be different to the one reported by single-molecule studies, due to the different experimental conditions. In particular, the DNA concentration used in the NMR studies is $10^{6}$-fold higher than the concentration used in the sm-FRET studies.

\section{Conclusions}

In conclusion sm-FRET analysis reveals that the binding of BTC can shift the equilibria of $\mathrm{K}^{+}$-free $c-M Y C$ and $h$-TELO DNA sequences, which existed as ensembles of unfolded and partially folded quadruplex structures, to a single folded conformation. FCS studies demonstrate that BTC alters the rod shaped DNA sequences into globular quadruplexes with a decrease in hydrodynamic radii. NMR analysis shows that BTC binds to a minor conformation of $c-M Y C$ by conformational selection, and is capable of promoting a restructuring of the loop-loop interactions in the basket conformation formed by $h$ TELO. These studies provide quantitative analysis of small molecule-mediated dynamic conformational changes of human G-quadruplexes that would be applicable for a range of interacting ligands with a variety of quadruplex forming sequences.

\section{Acknowledgements}

The authors thank Professor Shankar Balasubramanian for useful discussions. The authors thank DST, India (No. SB/S1/ OC-06/2014, Dated 12-03-2015), DST-Center for Ultrafast Spectroscopy and Microscopy (IR/S1/CU02/2009) and CSIR, India (CSIR: 02(0121)13/EMR-II) for funding. MD thanks DST for an inspire fellowship; SG and DP thank CSIR-India for research fellowships. HS and IB thank the state of Hesse (BMRZ, LOEWE project: Synchembio) for financial support.

\section{Notes and references}

1 G. W. Collie and G. N. Parkinson, Chem. Soc. Rev., 2011, 40, 5867-5892.

2 J.-L. Mergny and C. Helene, Nat. Med., 1998, 4, 1366-1367.

3 T. A. Brooks and L. H. Hurley, Nat. Rev. Cancer, 2009, 9, 849861.

4 S. Neidle and G. Parkinson, Nat. Rev. Drug Discovery, 2002, 1, 383-393.

5 S. Balasubramanian, L. H. Hurley and S. Neidle, Nat. Rev. Drug Discovery, 2011, 10, 261-275.

6 J. T. Davis, Angew. Chem., Int. Ed., 2004, 43, 668-698.

7 A. Siddiqui-Jain, C. L. Grand, D. J. Bearss and L. H. Hurley, Proc. Natl. Acad. Sci. U. S. A., 2002, 99, 11593-11598.

8 S. Rankin, A. P. Reszka, J. Huppert, M. Zloh, G. N. Parkinson, A. K. Todd, S. Ladame, S. Balasubramanian and S. Neidle, J. Am. Chem. Soc., 2005, 127, 10584-10589.

9 H. Fernando, A. P. Reszka, J. Huppert, S. Ladame, S. Rankin, A. R. Venkitaraman, S. Neidle and S. Balasubramanian, Biochemistry, 2006, 45, 7854-7860.

10 S. Neidle, FEBS J., 2010, 277, 1118-1125.

11 J. Seenisamy, S. Bashyam, V. Gokhale, H. Vankayalapati, D. Sun, A. Siddiqui-Jain, N. Streiner, K. Shin-Ya, E. White, W. D. Wilson and L. H. Hurley, J. Am. Chem. Soc., 2005, 127, 2944-2959.

12 S. Burge, G. N. Parkinson, P. Hazel, A. K. Todd and S. Neidle, Nucleic Acids Res., 2006, 34, 5402-5415.

13 E. Hatzakis, K. Okamoto and D. Yang, Biochemistry, 2010, 49, 9152-9160.

14 A. T. Phan, V. Kuryavyi, K. N. Luu and D. J. Patel, Nucleic Acids Res., 2007, 35, 6517-6525.

15 P. Murat, Y. Singh and E. Defrancq, Chem. Soc. Rev., 2011, 40, 5293-5307. 
16 J. J. Green, S. Ladame, L. Ying, D. Klenerman and S. Balasubramanian, J. Am. Chem. Soc., 2006, 128, 98099812.

17 K. W. Lim, S. Amrane, S. Bouaziz, W. Xu, Y. Mu, D. J. Patel, K. N. Luu and A. T. Phan, J. Am. Chem. Soc., 2009, 131, 43014309.

18 Z. Zhang, J. Dai, E. Veliath, R. A. Jones and D. Yang, Nucleic Acids Res., 2010, 38, 1009-1021.

19 J. Y. Lee, B. Okumus, D. S. Kim and T. Ha, Proc. Natl. Acad. Sci. U. S. A., 2005, 102, 18938-18943.

20 S. Weiss, Science, 1999, 283, 1676-1683.

21 A. A. Deniz, M. Dahan, J. R. Grunwell, T. Ha, A. E. Faulhaber, D. S. Chemla, S. Weiss and P. G. Schultz, Proc. Natl. Acad. Sci. U. S. A., 1999, 96, 3670-3675.

22 L. Ying, J. J. Green, H. Li, D. Klenerman and S. Balasubramanian, Proc. Natl. Acad. Sci. U. S. A., 2003, 100, 14629-14634.

23 T. Ha, Nat. Methods, 2014, 11, 1015-1018.

24 B. Saccü, Y. Ishitsuka, R. Meyer, A. Sprengel, E.-C. Schöneweiß, G. U. Nienhaus and C. M. Niemeyer, Angew. Chem., Int. Ed., 2015, 54, 3592-3597.

25 R. Tsukanov, T. E. Tomov, M. Liber, Y. Berger and E. Nir, Acc. Chem. Res., 2014, 47, 1789-1798.

26 A. Tanaka, J. Choi, S. K. Kim and T. Majima, J. Phys. Chem. B, 2013, 117, 6711-6717.

27 P. S. Shirude and S. Balasubramanian, Biochimie, 2008, 90, 1197-1206.

28 P. S. Shirude, L. Ying and S. Balasubramanian, Chem. Commun., 2008, 2007-2009.

29 P. S. Shirude, B. Okumus, L. Ying, T. Ha and S. Balasubramanian, J. Am. Chem. Soc., 2007, 129, 74847485.
30 P. V. Jena, P. S. Shirude, B. Okumus, K. Laxmi-Reddy, F. Godde, I. Huc, S. Balasubramanian and T. Ha, J. Am. Chem. Soc., 2009, 131, 12522-12523.

31 D. Koirala, S. Dhakal, B. Ashbridge, Y. Sannohe, R. Rodriguez, H. Sugiyama, S. Balasubramanian and H. Mao, Nat. Chem., 2011, 3, 782-787.

32 G. Bonnet, O. Krichevsky and A. Libchaber, Proc. Natl. Acad. Sci. U. S. A., 1998, 95, 8602-8606.

33 K. Ishii and T. Tahara, J. Phys. Chem. B, 2013, 117, 1142311432.

34 E. L. Elson and D. Magde, Biopolymers, 1974, 13, 1-27.

35 H. Neuweiler, C. M. Johnson and A. R. Fersht, Proc. Natl. Acad. Sci. U. S. A., 2009, 106, 18569-18574.

36 M. I. Wallace, L. Ying, S. Balasubramanian and D. Klenerman, J. Phys. Chem. B, 2000, 104, 11551-11555.

37 J. R. Grunwell, J. L. Glass, T. D. Lacoste, A. A. Deniz, D. S. Chemla and P. G. Schultz, J. Am. Chem. Soc., 2001, 123, 4295-4303.

38 J. Choi and T. Majima, Chem. Soc. Rev., 2011, 40, 5893-5909. 39 J. Choi, S. Kim, T. Tachikawa, M. Fujitsuka and T. Majima, J. Am. Chem. Soc., 2011, 133, 16146-16153.

40 D. Panda, M. Debnath, S. Mandal, I. Bessi, H. Schwalbe and J. Dash, Sci. Rep., 2015, 5, 13183.

41 A. De Cian, L. Guittat, M. Kaiser, B. Saccü, S. Amrane, A. Bourdoncle, P. Alberti, M.-P. Teulade-Fichou, L. Lacroix and J.-L. Mergny, Methods, 2007, 42, 183-195.

42 R. D. Gray, J. O. Trent and J. B. Chaires, J. Mol. Biol., 2014, 426, 1629-1650.

43 A. Ambrus, D. Chen, J. Dai, R. A. Jones and D. Yang, Biochemistry, 2005, 44, 2048-2058.

44 J. Dai, M. Carver, L. H. Hurley and D. Yang, J. Am. Chem. Soc., 2011, 133, 17673-17680. 